\title{
The role of inflammasomes in cutaneous pathology
}

\author{
Magdalena Ciążyńska ${ }^{1,2}$, Joanna Narbutt², Małgorzata Skibińska², Aleksandra Lesiak²
}

${ }^{1}$ Department of Proliferative Diseases, Nicolaus Copernicus Multidisciplinary Centre for Oncology and Traumatology, Lodz, Poland ${ }^{2}$ Department of Dermatology, Paediatric Dermatology and Oncology Clinic, Medical University of Lodz, Lodz, Poland

Adv Dermatol Allergol 2022; XXXIX (1): 39-46

DOI: https://doi.org/10.5114/ada.2022.113802

\begin{abstract}
Inflammasomes are large intracellular multiprotein complexes, which constitute a novel part of the innate immune system. In response to danger signals from pathogens or other harmful agents, inflammasomes assemble resulting in production of the inflammatory cytokines. We discuss recent knowledge of the role of deregulated inflammasome activity in skin pathologies such as autoinflammatory diseases as well as common skin diseases such as psoriasis and atopic dermatitis. We also present an insight into the activation and effector mechanisms of inflammasomes in skin carcinogenesis. The complex influence of inflammasome on cutaneous disorders raises new challenges and opportunities for the treatment of skin diseases.
\end{abstract}

Key words: inflammasome, skin disease, skin cancer.

\section{Introduction}

The skin is the largest organ of the human body, which constitutes the first and main barrier protecting the organism against invasion from pathogens, microbes and stress factors such as ultraviolet radiation (UVR) [1]. Keratinocytes (the main type of cells in the epidermis), in addition to their mechanical barrier function, are immunologically active, responding to injuries and danger signals by secreting proinflammatory cytokines.

Integrity and homeostasis of the skin may be maintained thanks to adequate defence mechanisms that include the epidermal barrier and appropriate innate immune responses. The inflammasome is a novel important part of the innate immune system originally reported as a molecular platform triggering inflammation in August 2002 [2]. Although the inflammation process is necessary for the clearance of harmful pathogens, its excessive extent could cause damage to healthy tissue [3]. Hence, since the discovery of inflammasomes, its role in maintaining an optimal balance of the host response to pathogens or stress factors in various diseases has been thoroughly analysed.

In this review, we present the role of inflammasome and its effector pathways in the pathogenesis of various types of skin diseases. The first part of the article provides basic data about inflammasomes. Subsequently, we discuss the main dermatological diseases in association with the role of inflammasomes. Then, we demonstrate inflammasomes as a skin tumour-promoting structure, despite its protective role in the development of different tumours such as colon cancer.

\section{Inflammasomes: basic information}

The inflammasome is a multicomponent cytosolic protein complex, which plays a crucial role in innate immunity by its specific functions to induce maturation of inflammatory cytokines such as interleukin 1 (IL-1 $1 \beta$ ) and interleukin 18 (IL-18) in response to pathogens, infection or other autogenous danger signals. Classically, inflammasome complexes are composed of three constant elements: a molecular pattern recognition receptor (PRR), an apoptosis-associated speck-like protein containing a caspase recruitment domain (ASC) and a caspase-1 enzyme $[2,4]$. Among the PRRs we can distinguish NODlike receptors (NLRs) that recognize and interact with pathogen-associated molecular patterns (PAMPs) and endogenous ligands or damage-associated molecular patterns (DAMPs) derived from normal tissues as well as tumour cells to induce autoimmune diseases or an antitumor response $[5,6]$.

Address for correspondence: Magdalena Ciążyńska, Department of Proliferative Diseases, Nicolaus Copernicus Multidisciplinary Centre for Oncology and Traumatology, 62 Pabianicka St, 93-513 Lodz, Poland, e-mail: ciazynska.magdalena@gmail.com Received: 23.12.2019, accepted: 25.04.2020. 
So far, many proteins which belong to the NLR family such as NLRP1, NLRP2, NLRP3, NLRP6, NLRP7, NLRP12, NLRC4, and AIM2 (absent in melanoma-2) have been reported to initiate assembling the formation of an inflammasome and in recent years have attracted a lot of attention [7]. The NLRP3 inflammasome is one of the best characterized and the most investigated complexes, which is formed by the NLR, ASC adapter protein and the effector molecule pro-caspase-1 [7]. Activation of inflammasomes and production of mature or active IL-1 $\beta$ and IL-18 are thought to require two sequential signals. The first stimulus is initiated by exogenous or endogenous molecules, which induce the expression of pro-IL-1 $\beta$ proteins and proforms of IL-18, while the second is triggered by very diverse activating stimuli, leading to the caspase1-dependent conversion of pro-IL-1 $\beta$ to mature IL-1 $\beta$ [8]. Upon stimulation with diverse endogenous or exogenous signals NLRP proteins interact with ASC and caspase-1 and undergo oligomerization creating huge protein complexes. Inflammasome assembly leads to self-cleavage of pro-caspase- 1 to an active form of caspase-1 enzyme and initiates processing of pro-IL-1 $\beta$ and pro-IL-18 into their mature and bioactive forms. This process induces several biological effects related to infection, inflammation and autoimmune responses [7]. Figure 1 presents an NLRP3 inflammasome assembly and activation.

In addition to the NLR-containing inflammasomes, AIM2 also assembles an inflammasome within a combination of ASC and caspase- 1 to induce the production of proinflammatory cytokines IL-1 $\beta$ and IL-18 $[9,10]$. Generally, various types of inflammasomes, except NLRP3, are characterized by defined stimuli and by models of activation patterns from pathogens. Therefore, the NLR proteins such as NLRP1, NLRP4, and NLRP6 and AIM2 assemble this complex in a stimulus-specific manner [11].

NLRP1 is currently thought to respond to muramyl dipeptide, and Bacillus anthracis lethal toxin [12]. In turn, AIM2 is regarded as a cytosolic DNA sensor, which forms an inflammasome in response to bacterial DNA, viral DNA as well as endogenous DNA released during cellular damage. In view of its specific potential to recognize host DNA, AIM2 activation may predispose to the development of autoimmune diseases such as psoriasis, arthritis or systemic lupus erythematosus [13, 14].

In contrast to the previously described inflammasomes the NLRP3 inflammasome can be activated in response to a broad spectrum of both exogenous (such as metabolic dysregulation, tissue damage, infection) [15] and endogenous molecules such as extracellular adenosine triphosphate (ATP), lipopolysaccharide (LPS), amyloid $\beta$ fibrils, hyaluronan, and uric acid crystals [16]. Interestingly, many studies proved that inflammasome NLRP3 signalling is activated in response to various infection pathogens including bacteria such as S. aureus, Neisseria gonorrhoeae, Escherichia coli, Vibrio cholera, and Chlamydia pneumoniae as well as the fungal, viral and parasites [17-19]. It seems improbable that many NLRP3 inflammasome activators can bind to the NLRP3
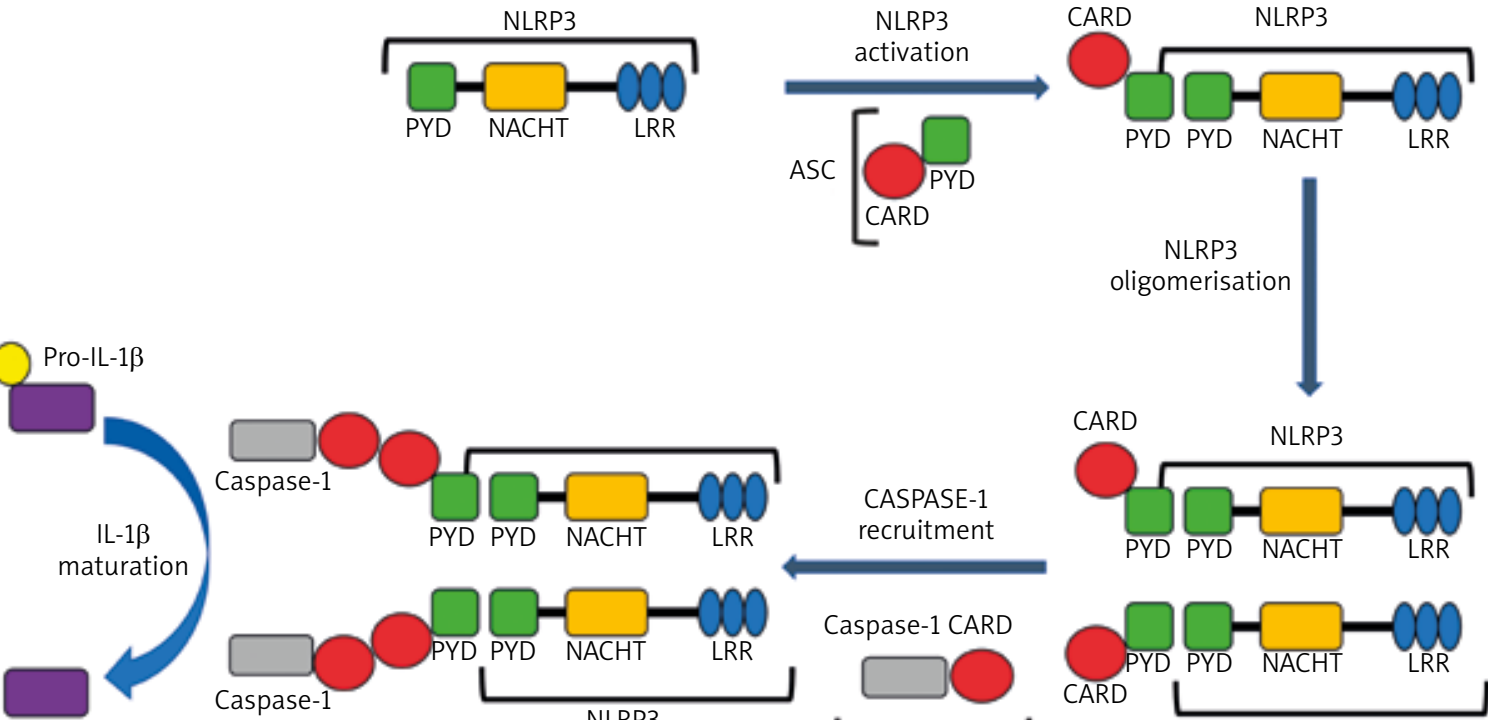

$\mathrm{IL}-1 \beta$
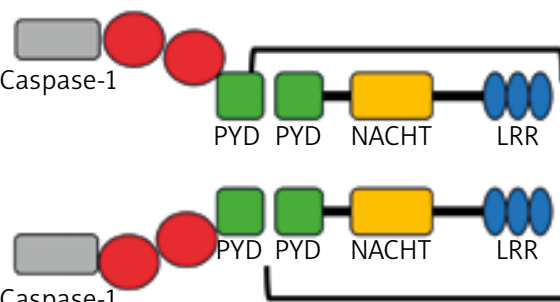

CASPASE-1 recruitment
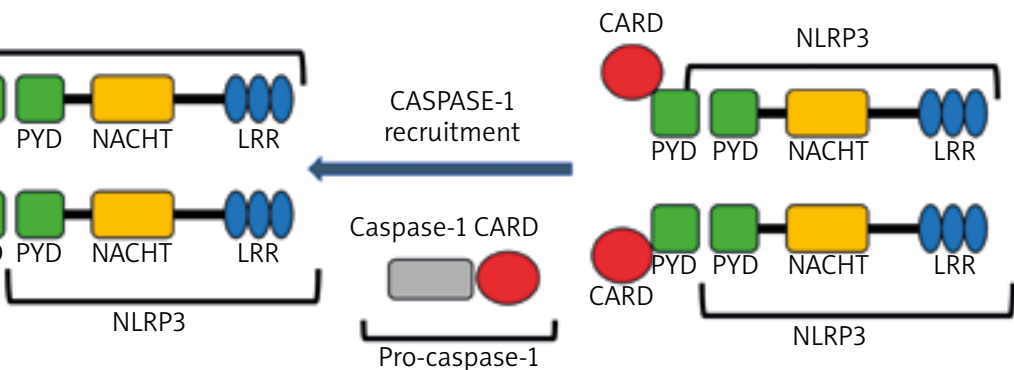

NACHT - nucleotide-binding and oligomerization domain, CARD - caspase recruitment domain, LRR - leucine rich repeat domain, PYD - pyrin domain, NLRP3 - NOD-like receptor pyrin domain-containing protein 3.

Figure 1. NLRP3 inflammasome assembly and activation. Upon activation, the NLRP3 protein interacts with adaptor protein ASC via the PYD domain and the CARD domain of ASC recruits the CARD domain of pro-caspase-1. The active complex of NLRP3-ASC-pro-caspase-1 is also named NLRP3 inflammasome. Finally, caspase-1 leads to activation via proteolytic cleavage of pro-IL-1 $\beta$ causing maturing of IL-1 $\beta$ 
structure to form the NLRP3 inflammasome complex. This suggests that microbes indirectly activate this complex by other DAMPS that are released or produced as a consequence of cellular or tissue injury elicited by toxins of the infectious agent [13]. Although, activation of NLRP3 remains still unclear, three underlying molecular mechanisms have been formulated such as: the K+ efflux, signalling accompanied by the generation of reactive oxygen species (ROS) and the third model depends on the rupture of lysosome [20].

Although scientific data support that the aberrant and uncontrolled activation of the inflammasomes is a risk factor for autoimmune, autoinflammatory and metabolic diseases, currently we have very limited knowledge of the intricate mechanisms responsible for this cytoplasmic complexes' activation and modulation during diseases and their therapies.

\section{Autoinflammatory diseases associated with skin symptoms}

Autoinflammatory diseases constitute a group of rare hereditary syndromes characterized by exacerbated responses of the innate immune system with usually insidious onset. Autoinflammatory disorders are characterized by systemic inflammation as well as clinical and laboratory features. The features observed in infectious and autoimmune diseases with specific tissue involvement including skin, joints, conjunctiva, as well as typical features of allergic diseases such as responses to external stimuli (cold exposure). The patients with autoinflammatory disorders demonstrate no evidence of pathogenic infection, and no indication of self-directed autoantibody, antigen specific $T$ cell or IgE mediated inflammation. This is a group of diseases that pathomechanism explains by disturbances in activating inflammasomes.

Most autoinflammatory diseases begin in childhood, even in infancy, rarely patients report the first symptoms in adulthood. A common feature of autoinflammatory diseases is recurrent symptoms such as fever. This group includes: cryopyrin-associated periodic syndrome (CAPS), PAPA syndrome (pyogenic arthritis, pyoderma, gangrenosum, acne), familial Mediterranean fever (FMF), Schnitzler syndrome, hyper-lgD syndrome (HIDS) and deficiency of IL-1 receptor antagonist (DIRA) [1]. Table 1 presents the most important information about autoinflammatory diseases that cause skin lesions in which inflammasomes are involved with highlighted mutations in genes that code for inflammasome component proteins and proteins that interact with the inflammasome.

\section{Cryopyrin-associated periodic syndrome}

The cryopyrin-associated periodic syndrome is a rare hereditary inflammatory disorder comprising three phenotype entities: familial cold autoinflammatory syndrome (FCAS), Muckle-Wells syndrome (MWS), and neonatal-onset multisystem inflammatory disease (NOMID). It is characterized by periodic fever associated with urticaria-like skin lesions [21-26].

CAPS results from a gain-of-function mutation of the NLRP3 gene (also known as CIAS1), which is located on chromosome 1q44, which leads to overproduction of interleukin- $1 \beta$ by macrophages, monocytes, and chondrocytes, resulting in inflammatory symptoms seen in CAPS [21]. Although each of these three entities proceeds in a specific manner, their symptoms may overlap. Clinical signs common to all three entities are urticaria, recurrent fever and pain or arthritis. FCAS is the mildest form of the spectrum while the most serious symptoms are connected with NOMID [21-26].

FCAS (previously called familial cold urticaria) represents the mildest phenotype characterized by recurrent urticaria, arthralgia, and fever, which tend to be less than of 12 h' duration and usually is connected to a general exposure to low ambient temperatures. Interestingly, limited exposure to ice does not trigger the lesions, which separates it from other syndromes that occur with urticaria and non-familial cold lesions. The exact mechanism through which the cold triggers the skin lesions is still unknown.

MWS is the intermediate phenotype of CAPS and presents with the same symptoms as FCAS, apart from the cold inflammation, which can be triggered by stress, exercise or even without clear provocation. Additionally, MWS can be associated with renal amyloidosis and sensorineural hearing loss during adolescence. Skin symptoms in MWS may last longer than $12 \mathrm{~h}$.

The clinical symptoms in NOMID are usually more severely expressed and more constant than those presented in FCAS or MWS. Skin rash, fever and malaise persist almost constantly. In addition, destructive arthritis develops often with massive and rapid hypertrophy of cartilage progressive ossification (especially patella). Another problem is the intense central nervous system changes: chronic aseptic meningitis, deafness, optic nerve atrophy and macular oedema, choroiditis and mental retardation. Some patients have facial dysmorphic manifestations: macrocephaly, prominent frontal tumours and flattened nose tip [22, 24, 25]. Because cryopyrin is also expressed in human chondrocytes, its increased secretion in NOMID results in arthropathy $[27,28]$.

The discovery of mutations in the NLRP3 gene and excessive expression of IL-1 are the key factors in the pathogenesis of CAPS. The beneficial effects of usage of IL-1 antagonists in CAPS have been recently demonstrated. Anakinra is a recombinant human IL-1 receptor antagonist blocking the inflammatory effects of IL-1, which has revolutionized the treatment of CAPS [29]. Canakinumab - a human monoclonal anti-IL-1 $\beta$ antibody and rilonacept - a dimeric fusion protein, are other registered therapeutic options in CAPS treatment. 
Table 1. Autoinflammatory diseases that cause skin lesions

\begin{tabular}{|c|c|c|c|c|c|c|c|}
\hline 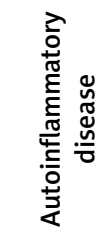 & 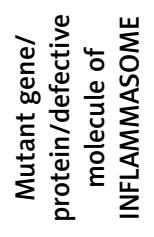 & 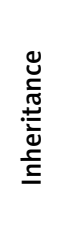 & 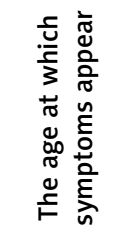 & 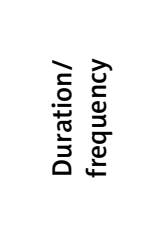 & 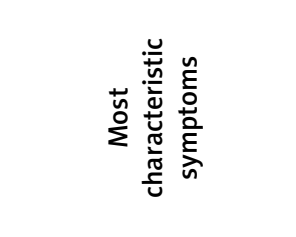 & $\begin{array}{l}\frac{c}{\bar{y}} \\
\frac{\bar{d}}{\bar{v}}\end{array}$ & 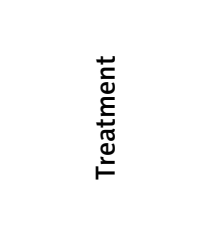 \\
\hline FCAS & $\begin{array}{l}\text { CIAS1/ } \\
\text { cryopyrin/ } \\
\text { NLRP3 }\end{array}$ & $A D$ & $\begin{array}{c}\text { Under } 6 \\
\text { y.o. }\end{array}$ & $\begin{array}{l}<24 \mathrm{~h} / \text { cold } \\
\text { induced } \\
\text { symptoms }\end{array}$ & $\begin{array}{l}\text { Fever, chills, urticaria- } \\
\text { like rash, severe joint } \\
\text { pain, conjunctivitis }\end{array}$ & $\begin{array}{c}\text { Maculopapular or urticarial, usually } \\
\text { not pruriginous, lesions that may } \\
\text { be painful }\end{array}$ & $\begin{array}{l}\text { IL-1 antagonists: } \\
\text { Anakinra } \\
\text { Rilonacept } \\
\text { Canakinumab }\end{array}$ \\
\hline MWS & $\begin{array}{l}\text { CIAS1/ } \\
\text { cryopyrin/ } \\
\text { NLRP3 }\end{array}$ & $A D$ & $\begin{array}{l}\text { Up to } 6 \\
\text { y.o. }\end{array}$ & $\begin{array}{l}24-48 \mathrm{~h} / \\
\text { frequent, } \\
\text { sometimes } \\
\text { almost } \\
\text { permanent }\end{array}$ & $\begin{array}{l}\text { Periodic weakness, } \\
\text { severe pain in the } \\
\text { limbs, rash, hives } \\
\text { similar, hearing loss, } \\
\text { amyloidosis }\end{array}$ & Generalized, non-itching urticaria & $\begin{array}{l}\text { IL-1 antagonists: } \\
\text { Anakinra } \\
\text { Rilonacept } \\
\text { Canakinumab }\end{array}$ \\
\hline NOMID & $\begin{array}{l}\text { CIAS1/ } \\
\text { cryopyrin/ } \\
\text { NLRP3 }\end{array}$ & $A D$ & $\begin{array}{l}\text { Up to } 6 \\
\text { y.o. }\end{array}$ & Constantly & $\begin{array}{c}\text { Fever, urticaria-like rash, } \\
\text { destructive arthropathy, } \\
\text { chronic meningitis, } \\
\text { hearing loss, optic } \\
\text { neuritis }\end{array}$ & Maculopapular or urticarial lesions & $\begin{array}{l}\text { IL-1 antagonists: } \\
\text { Anakinra } \\
\text { Canakinumab }\end{array}$ \\
\hline FMF & $\begin{array}{l}\text { MEFV/ } \\
\text { pyrin }\end{array}$ & $A R$ & $\begin{array}{l}\text { Under } 10 \\
\text { y.o. }\end{array}$ & $\begin{array}{l}\text { 1-3 days/ } \\
\text { every } 4-8 \\
\text { weeks }\end{array}$ & $\begin{array}{l}\text { Fever, peritonitis, } \\
\text { rosacea-like rash, } \\
\text { inflammation of } \\
\text { individual joints, } \\
\text { amyloidosis }\end{array}$ & $\begin{array}{l}\text { Skin lesions appear in up to } 43 \% \text { of } \\
\text { the cases; } \\
\text { classical manifestation is erysipeloid } \\
\text { erythema with well-defined } \\
\text { erythematous-oedematous plaques, } \\
\text { frequently on legs and feet; } \\
\text { pruriginous, urticarial lesions or } \\
\text { palmoplantar erythema may also } \\
\text { occur }\end{array}$ & $\begin{array}{l}\text { IL-1 antagonists: } \\
\text { Colchicine } \\
\text { Thalidomide }\end{array}$ \\
\hline HIDS & $\begin{array}{c}\text { MVK/ } \\
\text { mevalonate } \\
\text { kinase }\end{array}$ & $A R$ & $\begin{array}{l}6 \text { months } \\
\text { (median) }\end{array}$ & $\begin{array}{c}\text { 4-7 days/ } \\
\text { every 4-6 } \\
\text { weeks }\end{array}$ & $\begin{array}{l}\text { Fever, abdominal } \\
\text { pain, diarrhoea, } \\
\text { maculopapular rash, } \\
\text { swollen cervical lymph } \\
\text { nodes, sometimes } \\
\text { ulceration }\end{array}$ & $\begin{array}{l}\text { Erythematous maculopapular rash, } \\
\text { less commonly nodular rash }\end{array}$ & $\begin{array}{l}\text { NSAIDs } \\
\text { Corticosteroids } \\
\text { Receptor } \\
\text { antagonists } \\
\text { Leukotriene } \\
\text { IL-1 antagonists }\end{array}$ \\
\hline DIRA & $\begin{array}{l}\text { IL-1RN } \\
\text { gene/ } \\
\text { IL-1RA }\end{array}$ & $A R$ & $\begin{array}{l}\text { Present } \\
\text { at birth }\end{array}$ & Constantly & $\begin{array}{c}\text { Perinatal-onset } \\
\text { pustular dermatitis, } \\
\text { joint swelling, painful } \\
\text { osteolytic lesions, and } \\
\text { periostitis without } \\
\text { fever }\end{array}$ & $\begin{array}{l}\text { Perinatal-onset pustular dermatitis } \\
\text { Other reported skin changes included: } \\
\text { generalised ichthyosis-like changes; } \\
\text { nail changes - pitting, separation of nail } \\
\text { from nail bed; mouth ulcers; in } 1 \text { case - } \\
\text { pyoderma gangrenosum }\end{array}$ & $\begin{array}{l}\text { IL-1 antagonists: } \\
\text { Anakinra }\end{array}$ \\
\hline
\end{tabular}

AD - autosomal dominant, AR - autosomal recessive, NSAIDs - nonsteroidal anti-inflammatory drugs, FMF-familial Mediterranean fever, HIDS - hyper-IgD syndrome, DIRA - deficiency of IL-1 receptor antagonist, FCAS - familial cold autoinflammatory syndrome, MWS - Muckle-Wells syndrome, NOMID - neonatalonset multisystem inflammatory disease, CIASI1 - cold-induced autoinflammatory syndrome 1 gene, NLRP3 - NOD, leucine-rich repeat and pyrin domain containing protein 3, MEFV - Mediterranean fever gene, MVK -- Mevalonate kinase gene, IL-1RN-gene coding interleukin 1 receptor antagonist, IL-1RA - interleukin 1 receptor antagonist.

\section{Familial Mediterranean fever}

Familial Mediterranean fever (FMF) is the most common autoinflammatory disease that is inherited as a recessive trait. The FMF conditioning mutation gene (MEFV) is located on the short arm of chromosome 16p and is responsible for the synthesis of altered pyrins, leading to the defective inhibition of NLRP3, increased apoptosis and IL-1 $\beta$ transformations [24, 25]. In $80 \%$ of patients, the first symptoms occur before the age of 10 . The characteristic episodes of high fever, usually exceeding $38.5^{\circ} \mathrm{C}$ occur most often for 3 days in a row accompanied by serositis and synovitis. Skin involvement is not very common and is present in $14-43 \%$ of cases [24, 25]. Symptoms disappear spontaneously and patients feel healthy between the episodes.

\section{Psoriasis}

Currently, psoriasis is perceived as a systemic, inflammatory skin disease that fits the characteristics of an autoinflammatory profile where the innate and adaptive immune responses are activated [30]. The presence of 
neutrophils in skin lesions and the activation of the innate immune response are typical for both psoriasis and other autoinflammatory diseases. Moreover, IL-1 $\beta$ and IL-18 play a central role in the pathogenesis of many inflammatory skin diseases, including psoriasis. It was shown that polymorphisms of NLRP1, NLRP3, and CARD8, as well as negative regulators of caspase- 1 activation are connected to the susceptibility to the development of psoriasis [31, 32]. As abundant cytosolic DNA and increased AIM2 expression were detected in keratinocytes in psoriatic lesions but not in healthy skin, recently it was shown that cytosolic DNA can activate inflammasomes containing the DNA sensor AIM2 [33]. It was also revealed that caspase-1 expresses greater activity in psoriatic lesions when compared to non-lesional skin [34]. Greater expression of caspase-5 in skin lesions in comparison to healthy skin was also reported [35].

\section{Atopic dermatitis}

Keratinocytes produce both pro-IL-1 $\beta$ [36] and proIL-18 [37], however under normal skin conditions, endogenous caspase- 1 activity is lacking. In the transgenic mouse model, in which cutaneous epidermal cells, under specific pathogen-free conditions secreted an excess of IL-18, animals spontaneously developed atopic dermatitis-like skin lesions, while deletion of IL-18 protected against the development of skin eruptions [38].

Niebuhr et al. [39] noted that skin of patients with atopic dermatitis (AD) as well as patients who suffer from psoriasis is frequently colonized with Staphylococcus aureus (S. aureus), however only patients with AD suffer from bacterial superinfections with this pathogen. NLRP3 links staphylococcal a-toxin to caspase-1 activation through the formation of inflammasome leading consecutively to IL-1 $\beta$ secretion [40]. The authors showed that NLRP3 and caspase-1 expressions were reduced in patients with AD compared to psoriatic and healthy skin. Also, ASC protein was downregulated in AD lesions, whereas in normal human keratinocytes upregulation of NLRP3 was observed. Recently, it has been shown that herpes simplex virus 1 (HSV-1) also induces activation of the NLRP3 inflammasome and releases IL-1 $\beta$ [41]. Patients with $A D$ often suffer from eczema herpeticatum - a widespread infection caused by HSV-1, which could suggest that the mechanism underlying HSV-1 infection is an attenuated IL-1 $\beta$ response.

Interestingly, Bivik et al. [42] evaluated NLRP1, NLRP3, and CARD8 single nucleotide polymorphisms. Surprisingly, no association between atopic dermatitis and NLRP3 or CARD 8 was found. The correlation between NLRP1 and AD was statistically significant in the case-control study, but not in the familial case study. This may suggest that NLRP1 plays only a modest role in AD and it might be only one of many risk factors for the development of this disease.

\section{Lupus erythematous}

Systemic lupus erythematosus (SLE) is a chronic disease that causes inflammation in connective tissue, with frequent skin symptoms of an erythematous rash across the cheeks and bridge of the nose, so called butterfly rash. The cutaneous signs of the disease appear or worsen when exposed to sunlight. The correlation between the inflammasome and the systemic lupus erythematosus has been analysed recently. Keratinocytes from patients with cutaneous lupus showed an increased expression of IL-18 [43, 44]. Wen et al. [45] proved that IL-18 polymorphism was associated with a high risk of SLE development. In contrast, the role of IL-1 $\beta$ in cutaneous lupus is still unclear. A few studies found a relationship between IL-1 $\beta$ polymorphism and SLE that develops in childhood and adolescence [46], but it was not confirmed by other authors [47]. Considering that UVB radiation could stimulate the synthesis of IL- $\beta$ in keratinocytes, it is highly probable that inflammasomes may have an impact on photosensitivity often associated with SLE.

\section{Vitiligo}

Vitiligo is an autoimmune disease characterized by skin depigmentation caused by destruction of epidermal melanocytes during an innate immune response induced by reactive oxygen species. Polymorphisms of NLRP1 are observed in patients with vitiligo and its increased expression was detected at the edge of the lesional skin. Jin et al. [48] showed that variants of NALP1 were related to vulnerability to autoimmune and autoinflammatory diseases and their presence was connected with a higher risk of development of generalized vitiligo. Moreover, some authors [49] assessed the presence and intensity of NLRP1 expression in vitiligo lesional and perilesional skin to evaluate possible correlations between NLRP1 and IL-1 $\beta$ expression, lymphocytic infiltrates and disease activity. They suggested that the NLRP1 inflammasome expression could be a useful test for assessing disease activity.

\section{Acne, hidradenitis suppurativa, rosacea}

The role of the inflammasome in hidradenitis suppurativa, acne and rosacea has also been investigated. Enhanced expression of NLRP3, caspase- 1 and IL-1 $\beta$ was found in all of the above diseases. Kistowska et al. [50] showed that Propionibacterium acnes (present in acne) stimulates the activation of NLRP3 leading to IL-1 $\beta$ secretion. In the study conducted by Casas et al. [51], it was found that rosacea was associated with elevated Demodex folliculorum density and an increase in skin inflammation markers. Moreover, the authors suggested that IL-18 and ASC adaptor underexpression, in patients with rosacea, might be responsible for the loss of microbial homoeostasis [51]. 


\section{Inflammasomes and skin cancer}

Although numerous studies demonstrated that the inflammasomes play a crucial role in dermatological autoinflammatory diseases, their role in skin tumour progression remains still elusive. Arising evidence indicate that chronic inflammation is an important factor at all stages of carcinogenesis, including initiation, growth, invasion and metastases $[52,53]$. Despite multiple studies showing that inflammasome and its components provide protection against the development of e.g. colon cancer [54], recent studies indicate that inflammasomes may promote tumour progression in the skin cancer [55].

Until now, most studies have been carried out on mice. Drexler et al. [56] showed that IL-1R- and caspase1-deficient mice relatively rarely develop skin tumours induced by dimethylbenzanthracene (DMBA) and tetradecanoylphorbol acetate (TPA) compared to wild-type mice. Furthermore, the same authors examined the role of ASC protein in skin carcinogenesis. They revealed that mice with knockout of ASC molecules in myeloid cells are protected from developing DMBA/TPA-induced skin cancer. Surprisingly, the ablation of ASC in keratinocytes in a mice model caused the development of more tumours compared with wild-type controls. It suggests the dual role of ASC in skin carcinogenesis, as a tumour promoter in myeloid cells and a tumour suppressor in keratinocytes [56]. The authors also revealed loss of expression of ASC protein in human cutaneous squamous cell carcinoma (SCC).

In an independent study conducted in a mice model with induced SCC, Gasparoto et al. [57] found that the presence of the ASC and caspase-1 played a protective role against tumour development and progression [57]. On the other hand, it is well known that ultraviolet radiation, which is the main factor in the development of SCC, triggers the secretion of IL- $1 \beta$ dependent on activation of inflammasomes in keratinocytes [58]. According to Sanchez et al. [26], ASC protein has a dual role in human cell strains of primary and metastatic melanomas. In the early stage of melanomas, the ASC is a tumorigenesis inhibitor, while the same protein in metastatic melanomas could promote tumour progression [26].

Evaluating the human melanoma cells of advanced and intermediate stages of cancer, Okamoto et al. [59] showed that late stage human melanoma cell lines synthesized and secreted IL-1 $\beta$ through activated NLRP3 inflammasome without the need for exogenous stimulation. This is in contrast to melanomas in the early stages, where stimulation of IL-1R is needed to induce the production of IL-1 $\beta$ [59]. Previous reports showed that IL-1 $\beta$ is involved in tumour invasion and angiogenesis and that IL-1 $\beta$ synthesis is modulated by both NLRP1 and NLRP3 inflammasomes. Verma et al. [60] investigated the relationship between NLRP1 and NLRP3 polymorphisms and susceptibility to the development of melanoma and found a strong link between nodular melanoma and the NLRP1 variant [60].

Activation of inflammasomes is associated not only with the action of IL-1 $\beta$ but also with the increase in the secretion of other pro-inflammatory cytokines such as IL18 , and secretion disorders of many caspases involved in the activation of cell apoptosis signals. Increasing attention is paid to the role of inflammasomes in the process of complex mechanisms of pyroptosis activation. Including these issues in the manuscript would involve a comprehensive description of the detailed mechanisms of activation of many canonical and non-canonical inflammasome pathways, which may be an interesting topic for another review.

\section{Summary}

The understanding of the inflammasome activation mechanism and its role in caspase- 1 activation in a highly regulated manner is the first step in our understanding of innate immune processes. Still many important questions remain unanswered, including how an organism decides which inflammasome should be activated in specific conditions or under the influence of certain environmental factors and how this multitude of cytosolic protein complex signalling is intertwined with other immune pathways. Undoubtedly, the complex role of the inflammasome in cutaneous diseases raises new challenges and opportunities for the treatment of skin diseases.

\section{Acknowledgments}

This work was supported by the Medical University of Lodz [503/5-064-01/503-1]; and the National Centre of Science [grant no. 2017/27/B/NZ5/02011].

\section{Conflict of interest}

The authors declare no conflict of interest.

\section{References}

1. Gurung P, Kanneganti TD, Autoinflammatory skin disorders: the inflammasome in focus. Trends Mol Med 2016; 22: 545-64.

2. Martinon F, Burns K, Tschopp J. The inflammasome: a molecular platform triggering activation of inflammatory caspases and processing of prolL-beta. Mol Cell 2002; 10: 417-26.

3. Indramohan M, Stahlik C, Dorfleutner A. COPs and POPs patrol inflammasome activation. J Mol Biol 2018; 430: 153-73.

4. Dunn JH, Ellis LZ, Fujita M. Inflammasomes as molecular mediators of inflammation and cancer: potential role in melanoma. Cancer Lett 2012; 314: 24-33.

5. Lamkanfi M, Dixit VM. Mechanisms and functions of inflammasomes. Cell 2014; 157: 1013-22.

6. Zitvogel L, Kepp O, Galluzzi L, Kroemer G. Inflammasomes in carcinogenesis and anticancer immune responses. Nat Immunol 2012; 13: 343-51. 
7. Alcocer-Gómez E, Castejón-Vega B, Cordero MD, Stressinduced NLRP3 inflammasome in human diseases. Adv Protein Chem Structural Biol 2017; 108: 127-62.

8. Latz E. The inflammasomes: mechanisms of activation and function. Curr Opin Immunol 2010; 22: 28-33.

9. Hornung V, Ablasser A, Charrel-Dennis M, et al. AIM2 recognizes cytosolic dsDNA and forms a caspase-1-activating inflammasome with ASC. Nature 2009; 458: 514-8.

10. Fernandes-Alnemri T, Yu JW, Datta P, et al. AIM2 activates the inflammasome and cell death in response to cytoplasmic DNA. Nature 2009; 458: 509-13.

11. Lamkanfi M, Dixit V. Inflammasomes and their roles in health and disease. Ann Rev Cell Develop Biol 2012; 28: 137-61.

12. Boyden ED, Dietrich WF. Nalp1b controls mouse macrophage susceptibility to anthrax lethal toxin. Nat Genet 2006; 38: 240-4.

13. Choubey D, Panchanathan R. Absent in melanoma 2 proteins in SLE. Clin Immunol 2017; 176: 42-8.

14. Smith S, Jefferies C. Role of DNA/RNA sensors and contribution to autoimmunity. Cytokine Growth Factor Rev 2014; 25: 745-57.

15. Pressman BC. Biological applications of ionophores. Ann Rev Biochem 1976; 45: 501-30.

16. Guo H, Callaway JB, Ting PY. Inflammasomes: mechanism of action, role in disease, and therapeutics. Nat Med 2015; 21: 677-87.

17. Duncan JA, Gao X, Huang MT, et al. Neisseria gonorrhoeae activates the proteinase cathepsin B to mediate the signaling activities of the NLRP3 and ASC-containing inflammasome. J Immunol 2009; 182: 6460-9.

18. He X, Mekasha S, Mavrogiorgos N, et al. Inflammation and fibrosis during Chlamydia pneumoniae infection is regulated by IL-1 and the NLRP3/ASC inflammasome. J Immunol 2010; 184: 5743-54.

19. Kayagaki N, Warming S, Lamkanfi M, et al. Non-canonical inflammasome activation targets caspase-11. Nature 2011; 479: 117-21.

20. Liston A, Masters SL. Homeostasis-altering molecular processes as mechanisms of inflammasome activation. Nat Rev Immunol 2017; 17: 208-14.

21. Miyamae T. Cryopyrin-associated periodic syndromes: diagnosis and management. Paediatr Drugs 2012; 14: 109-17.

22. Dávila-Seijo P, Hernández-Martín A, Torrelo A. Autoinflammatory syndromes for the dermatologist. Clin Dermatol 2014; 32: 488-501.

23. Moghaddas F, Masters SL. Monogenic autoinflammatory diseases: cytokinopathies. Cytokine 2015; 74: 237-46.

24. Nguyen TV, Cowen EW, Leslie KS. Autoinflammation: from monogenic syndromes to common skin diseases. J Am Acad Dermatol 2013; 68: 834-53.

25. Braun-Falco M, Ruzicka T. Skin manifestations in autoinflammatory syndromes. J Dtsch Dermatol Ges 2011; 9: 232-46.

26. Sanchez GA, de Jesus AA, Goldbach-Mansky R. Monogenic autoinflammatory diseases: disorders of amplified danger sensing and cytokine dysregulation. Rheum Dis Clin North Am 2013; 39: 701-34.

27. Feldmann J, Prieur A, Quartier P, et al. Chronic infantile neurological cutaneous and articular syndrome is caused by mutations in CIAS1, a gene highly expressed in polymorphonuclear cells and chondrocytes. Am J Hum Genet 2002; 71: 198-203.

28. Liu R, Truax AD, Chen L, et al. Expression profile of innate immune receptors, NLRS and AIM2, in human colorectal cancer: correlation with cancer stages and inflammasome components. Oncotarget 2015; 6: 33456-69.

29. Koning HD, Bodar EJ, Simon A, et al. Beneficial response to anakinra and thalidomide in Schnitzler's syndrome. Ann Rheum Dis 2006; 65: 542-4.

30. Rivas Bejarano JJ, Valdecantos WC. Psoriasis as autoinflammatory disease. Dermatol Clin 2013; 31: 445-60.

31. Carlström M, Ekman AK, Petersson S, et al. Genetic support for the role of the NLRP3 inflammasome in psoriasis susceptibility. Exp Dermatol 2012; 21: 932-7.

32. Ekman AK, Verma D, Fredrikson M, et al. Genetic variations of NLRP1: susceptibility in psoriasis. Br J Dermatol 2014; 171: 1517-20.

33. Dombrowski Y, Peric M, Koglin S, et al. Cytosolic DNA triggers inflammasome activation in keratinocytes in psoriatic lesions. Sci Transl Med 2011; 3: 82ra38.

34. Johansen C, Moeller K, Kragballe K, Iversen L. The activity of caspase-1 is increased in lesional psoriatic epidermis. J Invest Dermatol 2007; 127: 2857-64.

35. Salskov-Iversen ML, Johansen C, Kragballe K, Iversen L. Caspase-5 expression is upregulated in lesional psoriatic skin. J Invest Dermatol 2011; 131: 670-6.

36. Mizutani H, Black R, Kupper TS. Human keratinocytes produce but do not process pro-interleukin-1 (IL-1) beta. Different strategies of IL-1 production and processing in monocytes and keratinocytes. J Clin Invest 1991; 87: 1066-71.

37. Stoll S, Muller G, Kurimoto M, et al. Production of IL-18 (IFNgamma-inducing factor) messenger RNA and functional protein by murine keratinocytes. J Immunol 1997; 159: 298-302.

38. Konishi H, Tsutsui H, Murakami T, et al. IL-18 contributes to the spontaneous development of atopic dermatitis-like inflammatory skin lesion independently of IgE/stat6 under specific pathogen-free conditions. Proc Natl Acad Sci USA 2002; 99: 11340-5.

39. Niebuhr M, Baumert K, Heratizadeh A, et al. Impaired NLRP3 inflammasome expression and function in atopic dermatitis due to Th2 milieu. Allergy 2014; 69: 1058-67.

40. Munoz-Planillo R, Franchi L, Miller LS, Nunez G. A critical role for hemolysins and bacterial lipoproteins in Staphylococcus aureus-induced activation of the NLRP3 inflammasome. J Immunol 2009; 183: 3942-8.

41. Johnson KE, Chikoti L, Chandran B. Herpes simplex virus 1 infection induces activation and subsequent inhibition of the IFI16 and NLRP3 inflammasomes. J Virol 2013; 87: 5005-18.

42. Bivik C, Verma D, Winge MC, et al. Genetic variation in the inflammasome and atopic dermatitis susceptibility. J Invest Dermatol 2013; 133: 2486-9.

43. Wittmann M, Macdonald A, Renne J. IL-18 and skin inflammation. Autoimmun Rev 2009; 9: 45-8.

44. Wang D, Drenker M, Eiz-Vesper B, et al. Evidence for a pathogenetic role of interleukin-18 in cutaneous lupus erythematosus. Arthritis Rheum 2008; 58: 3205-15.

45. Wen D, Liu J, Du X, et al. Association of interleukin-18 (-137G/ C) polymorphism with rheumatoid arthritis and systemic lupus erythematosus: a meta-analysis. Int Rev Immunol 2014; 33: 34-44.

46. Pontillo A, Reis EC, Liphaus BL, et al. Inflammasome polymorphisms in juvenile systemic lupus erythematosus. Autoimmunity 2015; 48: 434-7.

47. Wang B, Zhu JM, Fan YG, et al. The association of ILI $\alpha$ and IL1 $\beta$ polymorphisms with susceptibility to systemic lupus erythematosus: a meta-analysis. Gene 2013; 527: 95-101. 
48. Jin Y, Mailloux CM, Gowan K, et al. NALP1 in vitiligo-associated multiple autoimmune disease. N Engl J Med 2007; 356: 1216-25.

49. Marie J, Kovacs D, Pain C, et al. Inflammasome activation and vitiligo/nonsegmental vitiligo progression. Br J Dermatol 2014; 170: 816-23.

50. Kistowska M, Gehrke S, Jankovic D, et al. IL-1 drives inflammatory responses to Propionibacterium acnes in vitro and in vivo. J Invest Dermatol 2014; 134: 677-85.

51. Casas C, Paul C, Lahfa M, et al. Quantification of Demodex folliculorum by PCR in rosacea and its relationship to skin innate immune activation. Exp Dermatol 2012; 21: 906-10.

52. Hanahan D, Weinberg RA. Hallmarks of cancer: the next generation. Cell 2011; 144: 646-74.

53. Munn DH, Bronte V. Immune suppressive mechanisms in the tumor microenvironment. Curr Opin Immunol 2016; 39: 1-6.

54. Hu B, Elinav E, Flavell RA. Inflammasome-mediated suppression of inflammation-induced colorectal cancer progression is mediated by direct regulation of epithelial cell proliferation. Cell Cycle 2011; 10: 1936-9.

55. Zhai Z, Liu W, Kaur M, et al. NLRP1 promotes tumor growth by enhancing inflammasome activation and suppressing apoptosis in metastatic melanoma. Oncogene 2017; 36: 3820-30.

56. Drexler SK, Bonsignore L, Masin M, et al. Tissue-specific opposing functions of the inflammasome adaptor ASC in the regulation of epithelial skin carcinogenesis. Proc Natl Acad Sci 2012; 109: 18384-9.

57. Gasparoto TH, de Oliveira CE, de Freitas LT, et al. Inflammasome activation is critical to the protective immune response during chemically induced squamous cell carcinoma. PLoS One 2014; 9: e107170.

58. Feldmeyer L, Keller M, Niklaus G, et al. The inflammasome mediates UVB-induced activation and secretion of interleukin-1beta by keratinocytes. Curr Biol 2007; 17: 1140-5.

59. Okamoto M, Liu W, Luo Y, et al. Constitutively active inflammasome in human melanoma cells mediating autoinflammation via caspase-1 processing and secretion of interleukin-1beta. J Biol Chem 2010; 285: 6477-88.

60. Verma D, Bivik C, Farahani E, et al. Inflammasome polymorphisms confer susceptibility to sporadic malignant melanoma. Pigment Cell Melanoma Res 2012; 25: 506-13. 